REFERENCES AND/OR ACKNOWLEDGEMENTS

No conflict of interest.

\section{CPS-134 PREVALENCE ANALYSIS OF PATIENTS TREATED WITH TRIPTANS AT RISK OF DEVELOPING MEDICATION OVERUSE HEADACHE AND DEVELOPMENT OF A PRESCRIPTION OPTIMISATION STRATEGY}

MT Brieva Herrero, E Marquez-Fernández* , N Sánchez-Devicente.

\subsection{6/ejhpharm-2020-eahpconf.235}

Hospital Antequera, Hospital Pharmacist, Antequera, Spain Background and importance Medication overdose headache $(\mathrm{MOH})$ is a secondary headache disorder occurring on 15 or more days per month developing as a consequence of regular overdose of headache medication for more than 3 months.

The prevalence of $\mathrm{MOH}$ is approximately $1-2 \%$ and is higher in women than in men. Many medications used to treat headaches have the potential for causing MOH. Currently, $\mathrm{MOH}$ secondary to triptans is increasing and leads to $\mathrm{MOH}$ sooner than with other medications. Anxiety and depression may be risk factors for the evolution of migraine into $\mathrm{MOH}$.

Aim and objectives To determine the prevalence of patients treated with triptans at risk of $\mathrm{MOH}$ (regular intake for $\geq 10$ days/month for $>3$ months) and the profile in our health area; to identify and communicate to the prescribers those patients with overuse of triptans; and to inform all clinicians about MOH: aetiology, clinical features, diagnosis and treatment.

Material and methods We analysed the dispensation records of all patients treated with triptans over 3 months (June 2019September 2019). Data collected were sex, age, monthly intake frequency and co-medication. We alerted prescribers by email, including management and de-prescription recommendations for $\mathrm{MOH}$. We posted content about $\mathrm{MOH}$ in our blog. Results The prevalence of patients treated with triptans was $0.50 \%$; 47 of 538 patients taking triptans $(8.7 \%)$ were at risk of $\mathrm{MOH}$. Their median age was 55 years and most were women (79\%). Median monthly intake was 16 doses (10-48). Thirty patients (64\%) had prescriptions for anxiety and/or depression and 13 patients (28\%) had preventive therapy prescriptions for headache. Twenty-nine prescribers were notified by email. Dispensation record history, co-medication, $\mathrm{MOH}$ management guide and patient education leaflets were attached.

Conclusion and relevance $\mathrm{MOH}$ is a common problem in clinical practice that needs to be properly managed to increase the likelihood of successful chronic daily headache treatment. The results obtained in our population were similar to published studies, both in prevalence and in patient profile. However, the $\mathrm{MOH}$ rate was still lacking as it needs a clinician diagnosis. In 6 months we will collect information about the evolution of these patients, and we expect that our intervention will lead to treatment optimisation, better use of triptans and headache relief.

\section{REFERENCES AND/OR ACKNOWLEDGEMENTS}

No conflict of interest.
4CPS-135 PERPHENAZINE AND PROPRANOLOL POISONING: A CASE REPORT

CA Alonso Peralta*, T Gimenez Poderós, D Gómez, RM González Franco, B Rogado Vegas, J Casanova Vázquez, M Rioja Carrera, P Del Rio Ortega, L Perez-Periañez Orrillo, I Aragon Gracia, M Valero Domínguez. Hospital Universitario Marqués De Valdecilla, Farmacia Hospitalaria, Santander, Spain

\subsection{6/ejhpharm-2020-eahpconf.236}

Background and importance The combination of perphenazine, a typical antipsychotic, with propranolol, a beta adrenergic antagonist, increases the concentrations of both drugs by pharmacokinetic interaction. ${ }^{1}$ The main effect of the interaction is potentiation of the hypotensive effect. Typical antipsychotics have an anticholinergic and antihistamine effect that can cause drowsiness, but also have structural similarities with benzodiazepines.

Aim and objectives To describe the clinical case of a patient with drug poisoning and the interaction between perphenazine and propranolol and its haemodynamic and CNS depressant effects.

Material and methods The patient was a 64-year-old woman who was found at home by the emergency ambulance service with a Glasgow coma scale (GCS) score of 3. Anamnesis showed autolytic attempt. Home treatment was letrozole 2.5 mg every 24 hours orally, perphenazine $8 \mathrm{mg}$ every 12 hours orally, losartan $50 \mathrm{mg}$ /hydrochlorothiazide $12.5 \mathrm{mg}$ every 24 hours orally, propranolol $10 \mathrm{mg}$ every 6 hours orally and paracetamol $325 \mathrm{mg} /$ tramadol $37.5 \mathrm{mg}$ every 8 hours orally.

During transfer to hospital, flumazenil $1 \mathrm{mg}$ was administered intravenously (IV) and GCS changed to 9-10. The patient was admitted to the intensive care unit due to a decreased level of consciousness and haemodynamic instability. Drug tests (toxicology screens) on blood and urine were requested. Endotracheal intubation and gastric lavage were performed. Pinkish content came out and it was thought to be traces of propranolol tablets.

For haemodynamic control, dobutamine was administered at $5 \mu \mathrm{g} / \mathrm{kg} / \mathrm{min}$ IV perfusion and antidotes to possible pharmacological intoxication were given: glucagon was administered at $0.03 \mathrm{mg} / \mathrm{kg} /$ hour perfusion IV (beta blockers), flumazenil bolus $1 \mathrm{mg}$ IV (benzodiazepines) and naloxone $0.4 \mathrm{mg}$ bolus IV (opioids).

Results Drug tests showed positive urine and blood levels of $84.1 \mathrm{~g} / \mathrm{L}$ for benzodiazepines. In the anamnesis she did not take benzodiazepines. Dobutamine, glucagon and naloxone were stopped because of the test results and haemodynamic improvement. Flumazenil $1 \mathrm{mg}$ bolus IV was administered again and an infusion of flumazenil was started at $0.5 \mathrm{mg} /$ hour IV until the level of consciousness was regained and the patient answered verbal orders on what happened 4 hours later.

Conclusion and relevance Perphenazine can produce possible false positives for benzodiazepines. The interaction between perphenazine and propranolol can trigger haemodynamic instability and CNS depression, which can be successfully managed with dobutamine, glucagon and flumazenil.

\section{REFERENCES AND/OR ACKNOWLEDGEMENTS}

1. Lexicomp: Interactions. Perphenazine-propranolol. Available at: https://online.lexi. com/lco/action/interact

No conflict of interest. 